\title{
IMPROVING THE QUALITY OF MANUFACTURING PRODUCTS WITH THE APPLICATION OF LEAN SIX-SIGMA
}

\author{
H Harisupriyanto ${ }^{1)}$, Yudha Prasetiawan ${ }^{2)}$, M Ferdian Rahma Supriyanto ${ }^{3)}$ \\ Jurusan Teknik Industri, Fakultas Teknologi Industri, ITS Surabaya \\ Kampus Keputih Sukolilo Surabaya 60111 \\ Email : ${ }^{1}$ hariqive@yahoo.com
}

\begin{abstract}
Product quality is an important factor that underlies the consumer's decision to choose the desired product and service. Quality can initially be determined by the company, but in subsequent developments, quality planning must pay attention to the wants and needs of consumers. In providing excellent service to customers, the company needs to apply the concept of lean thinking, intending to reduce waste. A methodology is needed that can reduce product variations, and production process errors with the Six Sigma methodology. The second application is often called Lean Six Sigma. This paper aims to improve the quality of fluid carrier tank products. The number of defective products, mainly on welding, cutting and bending process, so rework is needed that causes companies to suffer losses. The company expects to reduce product defects by less than 5\%. The welding, cutting and bending process are the highest contributor to defective products, so that process improvement is limited to these processes. The process of welding, cutting and bending process is considered a major problem, so the main concern for quality improvement is for the main problem. Sigma, the initial welding, cutting and bending process in sequence is quite good. The target to be achieved is to increase the sigma value of both processes. The alternative is chosen, namely creating and supervising SOPs, and training to improve the skills, knowledge, and abilities of each employee. These alternatives can increase the sigma value from the initial conditions from 2.93 to 3.20. The increase in sigma value indicates a decrease in the level of defects per million opportunities (DPMO).
\end{abstract}

Keywords: lean, waste, Sigma, defect, DPMO.

\section{Pendahuluan}

Kebutuhan pasar dan konsumen yang semakin dinamis, dengan pertumbuhan ekonomi akhir-akhir ini adalah peluang besar untuk memanfaatkan keunggulan bersaing. Bagi perusahaan peningkatkan skala ekonomi adalah basis untuk mendapatkan margin keuntungan, dan menjadikan daya saing sebagai momentum untuk memacu pertumbuhan produksi [1]. Pertumbuhan produksi yang meningkat diharapkan dapat menstimulus perkembangan sumber daya manusia, teknologi dan mengatasi masalah tenaga kerja. Dibutuhkan pemikiran untuk membangun keunggulan kompetitif, yang menjadi dasar baru bagi peningkatan daya saing bisnis [2]. Rangkaian aktivitas kualitas dapat dikategorikan sebagai sebuah domain problem yang sangat kompleks. Ini dapat dimulai dari aspek material sampai produk siap untuk dikirimkan ke konsumen. Kerumitan permasalahan ini akan mengarah pada kesalahan/ cacat produk atau kesalahan di dalam pengelolaan kualitas produk, apabila dari awal proses tidak mendapat perhatian serius secara integratif dan komprehensif [3;4]. Penggambaran proses pelayanan, biasanya dilakukan melalui pengkajian pemetaan proses. Pemetaan ini berupa pemetaan yang mencakup proses sejak pertama kali material dibeli sampai terselesainya proses menjadi produk atau jasa [5;6]. Bahkan setelah transaksi terselesaikan masih terdapat pelayanan yang dapat dikategorikan sebagai after sales service. 
Program kontrol kualitas mengamanatkan pelatihan karyawannya dalam semua aspek di dalam proses organisasi. Setiap proses bisnis yang menggabungkan kualitas dengan Six Sigma harus disempurnakan secara berkesinambungan dan proses ini membutuhkan pelatihan [7].

Pengendalian kualitas adalah aktivitas keteknikan dan manajemen, yang dengan aktivitas tersebut dapat diukur ciri-ciri kualitas dari produk, membandingkannya dengan spesifikasi atau persyaratan, dan mengambil tindakan penyehatan yang sesuai apabila terdapat perbedan antara penampilan yang sebenarnya dengan standart [8; 9]. Untuk itu perusahaan dituntut dapat menghasilkan kualitas produk yang konsisten agar dapat memenuhi kebutuhan pelanggan. Pengawasan terhadap produk mutlak dilakukan sebagai jaminan pada konsumen bahwa produk yang diterima konsumen memiliki mutu yang selalu baik. Proses ini termasuk di dalam kegiatan pengendalian kualitas [10].

Penelitan ini akan memberikan solusi terhadap permasalahan kualitas produk furniture. Dengan mengedepankan peranan perbaikan yang berkesinambungan (continuous improvement). Untuk itu dicoba untuk mengidentifikasi system atau quality requirements dari domain problem dengan tujuan menentukan prioritas perbaikan $[11 ; 12]$. Adapun tujuannya adalah identifikasi waste yang paling berpengaruh, dan memberikan usulan perbaikan yang bertujuan untuk mereduksi terjadinya waste

\section{Metodologi Penelitian}

Siklus Six-Sigma dipakai untuk membangun continous process improvement. Siklus yang dipakai adalah Define, Measure, Analysis dan Control seperti ditunjukkan pada gambar 1.

Define phase dimulai dengan pembuatan peta aliran proses dengan value stream mapping (VSM), untuk mengetahui proses yang mengindikasikan permasalahan. Ini didukung oleh voice of customer VOC). Metoda yang dipakai untuk menentukan problem adalah dalam bentuk waste (pemborosan) di sepanjang aliran proses produksi. Yang menjadi acuan untuk perbaikan adalah pendekatan lean thinking/ manufacturing. Lean manufacturing merupakan pendekatan sistematis untuk mengidentifikasi dan mengeliminasi waste melalui perbaikan yang berlanjut dari produk untuk memenuhi permintaan konsumen secara sempurna.

Measure phase dimulai dengan mengukur tingkat kinerja sekarang dengan defect per million opportunities (DPMO) dan nilai sigma. Analisys phase dimulai dengan mencari dan menentukan penyebab dari suatu masalah. Selanjutnya akar utama suatu permasalahan dapat dianalisis menggunakan diagram sebab akibat, root cause analisys (RCA) dan failure modes and effect analysis (FMEA).

Improvement phase diperoleh dari nilai risk priority number (RPN) dari FMEA. Merupakan fase meningkatkan proses dan menghilangkan sebab-sebab timbulnya cacat. Setelah sumber-sumber penyebab masalah kualitas dapat diidentifikasi, maka dapat dilakukan penetapan rencana tindakan (action plan) untuk melaksanakan peningkatan kualitas.

Control phase merupakan dokumentasi dari hasil-hasil peningkatan kualitas dan disebarluaskan. Hasil-hasil yang memuaskan dari proyek peningkatan kualitas sigma harus distandarisasikan, dan selanjutnya dilakukan peningkatan terus menerus. Seluruh fase tersebut dapat dilihat pada siklus dmaic, gambar 1.

Lean manufacturing adalah suatu strategi untuk dapat berproduksi pada level yang tinggi dengan persediaan yang minimal. Eight waste dipilih untuk menjadi runutan mencari critical waste. 


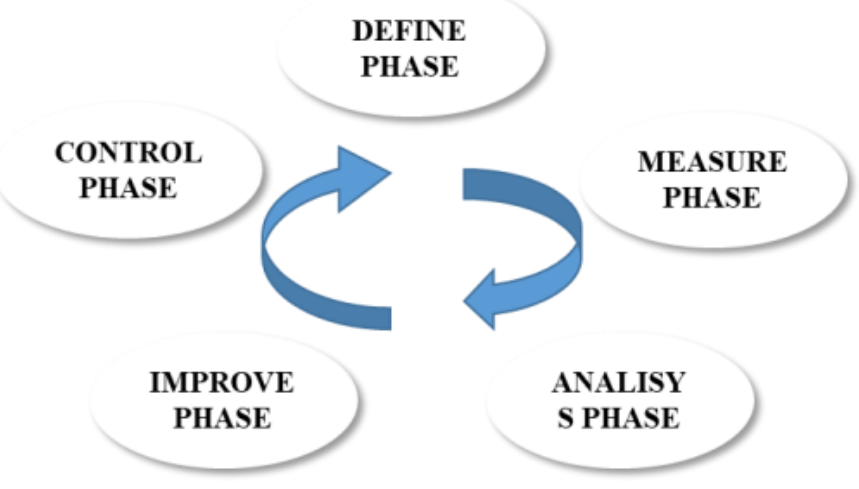

Gambar 1. Siklus DMAIC

Waste dapat diidentifikasikan sebagai idle time yang terjadi selama proses terjadi dan tidak mempunyai nilai tambahnya. Strategi yang benar dari lean manufacturing adalah dapat mengurangi biaya dan meningkatkan kualitas. Kekuatan dari kedua konsep ini disinergikan menjadi satu konsep yang tertintegrasi yaitu Konsep Lean Six Sigma [9; 13].

Pemikiran Lean Six Sigma perlu disebarluaskan ke seluruh bagian tanpa memandang tipe industri atau tipe kegiatan $[14 ; 15]$. Dengan demikian Lean Six Sigma dapat diterapkan dalam semua proses. Lean Six Sigma yang diterapkan dalam industri manufaktur akan menjadi Lean Six Sigma Manufacturing. Keterkaitan kedua konsep dapat dilihat pada gambar 2.

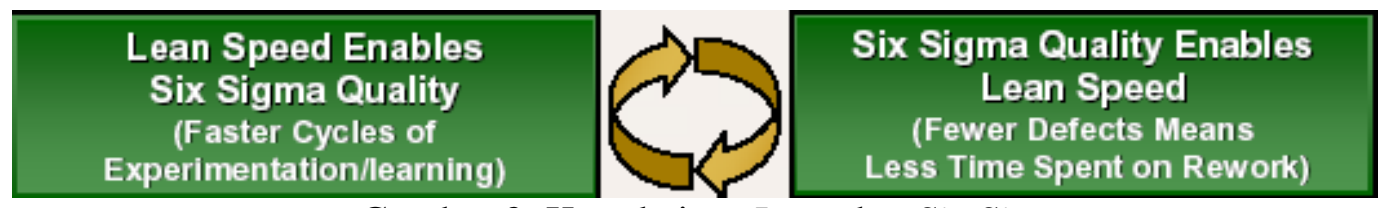

Gambar 2. Keterkaitan Lean dan Six Sigma

Tahapan terpenting adalah mencari penyebab munculnya critical to quality (CTQ) yang merupakan problem utama. Tools yang digunakan adalah Roots Cause Analysis-RCA [16; 17], dan FMEA (Failure Mode and Effect Analysis). Setelah itu dilakukan penyusunan rancangan perbaikan untuk mengurangi kegagalan pada proses. Penetapan usulan perbaikan didasarkan pada nilai Risk Priority Number (RPN) tertinggi [18; 19]. Selanjutnya FMEA digunakan untuk mengidentifikasi tindakan-tindakan korektif.

\section{Hasil dan Pembahasan}

Produk amatan yang dianalisis adalah proses pembuatan tangki. Tangki digunakan untuk mengangkut muatan yang bersifat cair (liquid). Ukuran kapasitas tangki truk yang diproduksi pun berbeda-beda mulai dari 5000 liter, 7000 liter, dan 8000 liter. Proses produksi tangki truk dibagi menjadi enam tahap yaitu proses cutting, bending, welding, finishing, assembly dan shipping. Proses prroduksi tersebut dapat digambarkan dalam bentuk value stream mapping, seperti pada gambar 3. Proses produksi tangki mempunyai total lead time selama 76 jam atau 9,62 hari. Berdasarkan hasil pengamatan, masih banyak ditemukan non value added activity yang mengindikasikan pemborosan (waste) terutama pada proses welding, cutting dan bending.

Tahap awal dari siklus DMAIC adalah define (D). Dari data historis yang berhubungan dengan repair/ rework proses dari departemen produksi di perusahaan maka dapat dilihat bahwa persentase terjadinya produk cacat lebih dari 5\% dari total produksi perusahaan. Angka ini dianggap perusahaan adalah cukup besar mengingat biaya rework yang harus dikeluarkan perusahaan selama ini cukup besar pula. Oleh sebab itu diperlukan suatu tindakan perbaikan 
secara kontinyu-terus menerus untuk mengurangi persentase cacat yang terjadi dengan tujuan untuk mereduksi biaya dan mencapai zero defect [1].

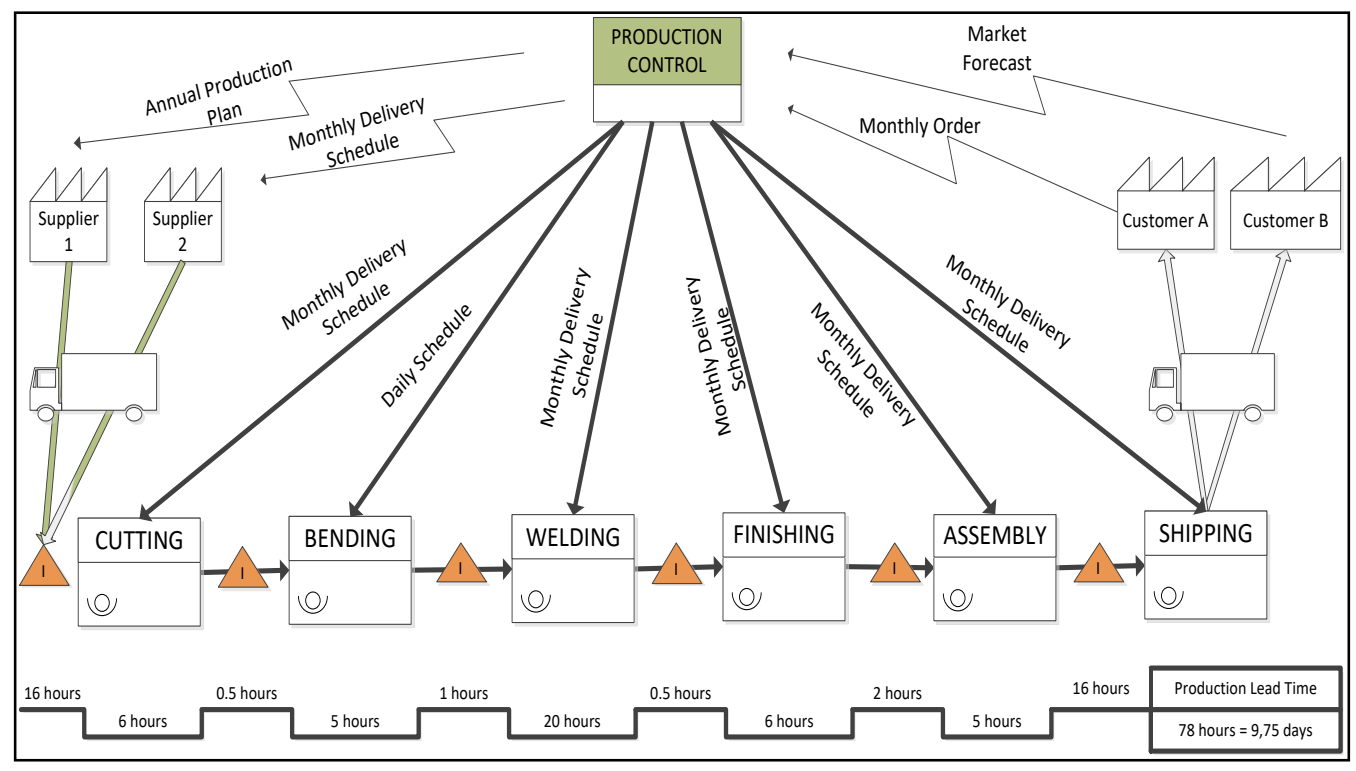

Gambar 3. VSM proses pembuatan tangki

Untuk mengetahui sistem produksi secara keseluruhan dapat dilakukan dengan cara menvisualisasikan aliran informasi dan aliran material ke dalam mapping. Salah satu mapping yang dipakai untuk menggambarkan sistem produksi adalah pembuatan Big Picture Mapping (BPM). Kecacatan biasanya disebakan oleh aktifitas atau proses yang tidak sesuai atau sering digambarkan karena adanya waste, di sepanjang proses produksi. Lean manufacturing merupakan sebuah konsep berpikir dalam manufaktur untuk mengurangi terjadinya non value added activity. Konsep ini mengarahkan setiap pelaku bisnis dunia manufaktur untuk mengklasifikasikan terlebih dahulu aktivitas-aktivitas di sepanjang proses. Sementara itu tipe aktivitas dalam organisasi $[14 ; 20]$ dapat diklasifikasikan dalam aktifitas yang value adding (VA), necessary but not value adding (NNVA), dan non value adding (NVA).

Bila seluruh aktifitas dihubungkan dengan proses maka seluruh aktifitas tersebut dapat diklasifikasikan pada ketiga aktifitas tersebut. Untuk menganalisa performansi manufaktur perusahaan, diperlukan sebuah pengukuran yang berbasis KPI (Key Performance Indicator). Indikator dalam pengukuran KPI ini dapat merepresentasikan hasil operasi manafuktur. Terdapat enam indikator yaitu produktifitas, kualitas, biaya, pengiriman, safety, dan moral. Namun KPI yang digunakan dibatasi hanya pada 4 (empat) pengukuran indikator yaitu produktifitas, kualitas, biaya, dan safety.

Setelah dilakukan pengklasifikasian aktivitas diperoleh hasil akhir dimana value added activity adalah $22 \%$, necessary but non value added activity yaitu $44 \%$ dan non value added activity adalah 34\%. Hasil ini menunjukkan bahwa proses produksi tangki masih banyak mengandung non value added activity. Aktivitas non value added ini mengindikasikan adanya waste.

Secara garis besar non value added yang terjadi pada proses welding, seperti welding dilakukan berulang-ulang. Pada proses cutting terdapat tiga aktivitas non value added; pemotongan dan pengecekan ulang pada material yang sedang diproses, membersihkan scrap dan menata ulang material yang tidak terpakai. Sedangkan pada proses bending, terjadi proses rework terhadap tingkat kelengkungan material. Aktivitas non value adding adalah aktivitas yang bersifat boros (waste). 
Aktifitas ini yang menyebabkan kecacatan produk yang dihasilkan. Untuk itu diperlukan sebuah cara agar nonvalue adding activity dapat direduksi. Apabila nonvalue adding activity dapat dikurangi maka tujuan utama berupa lead time prosess/ prodduksi akan menjadi lebih pendek.

Identifikasi waste dilakukan berdasarkan 4 KPI produksi yang telah ditetapkan yaitu produktivitas, kualitas, biaya dan safety. Identifikasi waste berpatokan pada sembilan tipe waste, yaitu E-DOWNTIME waste. Jenis waste ini meliputi Environmental, Healthy, and Safety (EHS), Defect, Over Production, Waiting, Not utilizing employee, Transportation, Inventory, Motion, dan Excess/ over processing.

Indikator produktivitas lebih menekankan pada efisiensi selama proses produksi. Identifikasi pengelompokan waste yang tergolong dalam KPI produktivitas antara lain defect, waiting, not utilizing employee, motion dan Excess/ over processing.

Waiting waste merupakan jenis pemborosan karena aktivitas menunggu. Ini berhubungan dengan kejadian downtime mesin yang menyebabkan proses produksi tertunda. Kejadian downtime dalam sebuah perusahaan dapat dibagi menjadi dua yaitu planned downtime dan unplanned downtime.

Over processing merupakan jenis pemborosan karena langkah-langkah proses yang lebih panjang dari yang seharusnya. Termasuk dalam waste ini yaitu aktivitas yang dilakukan secara berulang-ulang (rework). Terjadi proses rework terhadap 3 proses produksi tangki yaitu pada proses cutting, bending, dan welding. Dengan rata-rata proses total waktu rework yang terjadi yaitu 16.25 jam.

Indikator kualitas merupakan KPI yang berhubungan dengan spesifikasi dari customer. Indikator kualitas diukur berdasarkan jumlah defect. Dimana semakin banyak defect dapat diklasifikasikan dalam kualitas yang rendah dan sebaliknya.

KPI biaya merupakan indikator yang mengukur seluruh biaya produksi dan operasional perusahaan. Dalam perhitungan KPI biaya, pengukuran dapat dilakukan pada over production, transportation dan inventory waste. Over production merupakan jenis pemborosan yang terjadi karena produksi melebihi kuantitas. Pengukuran waste ini dilakukan berdasarkan aktivitas logistik. Waste ini diukur dari tingkat keterlambatan delivery kepada pelanggan. Pengukuran inventory waste berhubungan dengan warehousing mulai dari material masuk sampai material keluar dari warehouse.

Pengukuran indikator safety dapat dilakukan dengan menghitung seberapa banyak kecelakaan kerja selama produksi. KPI safety berhubungan dengan environmental, health and safety (EHS) waste.

Waiting waste ditentukan berdasarkan downtime mesin. Tahapan awal yaitu menghitung nilai sigma terhadap waiting. Sigma waiting dihitung terhadap total waktu waiting terhadap total waktu produksi secara keseluruhan.

Diperoleh bahwa total waktu unplanned downtime yang terjadi selama delapan periode produksi yaitu 48 jam adalah 416 jam. Dengan demikian persentasi sebesar $11.47 \%$. Berdasarkan perhitungan nilai sigma, untuk sigma waste waiting sebesar 3.27. Selanjutnya untuk menentukan biaya karena waiting waste berdasarkan pada biaya bertambahnya tenaga kerja karena bertambahnya waktu produksi. Diketahui bahwa total kerugian downtime mesin sebesar Rp 919.420.

Pengukuran Over processing waste berdasar pada jumlah rework yang terjadi selama proses produksi. Rework terjadi pada proses cutting, bending, dan welding. Berdasarkan waktu rework, persentase terjadinya rework yaitu sebesar $25 \%$ dari total production time 498 jam selama 8 periode produksi. Berdasarkan perhitungan sigma diperoleh bahwa nilai sigma pada waste Over processing pada aktivitas rework yaitu sebesar 3.47. Biaya kerugian yang ditanggung oleh pihak perusahaan yaitu sebesar Rp 3.831.494. 
Pengukuran defect waste berdasar pada jumlah defect yang terjadi selama proses welding yaitu sebesar $30 \%$. Nilai sigma pada defect waste sebesar 2.93. Biaya kerugian yang ditanggung akibat terjadinya defect pada proses welding yaitu sebesar Rp. 1.414.705

Pemilihan terhadap waste menunjukkan bahwa Excess/ over processing waste merupakan waste yang memiliki kerugian finansial yang paling besar yaitu sebesar Rp 3.831.494 selanjutnya waste defect dengan kerugian sebesar Rp 1.414 .705 dan yang terakhir merupakan waste waiting dengan kerugian finansial sebesar Rp 919.420.

Penyebab waiting waste berdasarkan downtime mesin. Dari pareto-chart diperoleh bahwa yang paling berpengaruh yaitu proses welding dan cutting menunjukkan kontribusi $80 \%$ terhadap terjadinya proses waiting. Tabel 4. menunjukkan proporsi waste.

Tabel 1. Peringkat waste berdasarkan proporsinya

\begin{tabular}{|l|c|l|l|}
\hline \multicolumn{1}{|c|}{ ienis waste } & $\%$ & \multicolumn{1}{|c|}{ ienis waste } & $\%$ \\
\hline $\begin{array}{l}\text { Excess/ Over processing } \\
\text { (proses berlebih) }\end{array}$ & 25 & $\begin{array}{l}\text { Underutilized human (kinerja } \\
\text { tidak maksimal) }\end{array}$ & 8 \\
\hline Defects (cacat produk) & 23 & Movement (gerakan operator) & 7 \\
\hline Waiting(waktu tunggu) & 18 & $\begin{array}{l}\text { Unnecessary inventory(inventory } \\
\text { berlebih) }\end{array}$ & 6 \\
\hline Transportation (perpindahan) & 8 & Over production (kelebihan & 5 \\
\hline
\end{tabular}

Dari tabel di atas diambil 3 (tiga) critical waste yang menjadi dasar untuk continous process improvement. Tiga critical waste tersebut adalah overprocessing waste, defects waste dan waiting waste.

Selanjutnya dibuat root cause analysis terhadap terjadinya downtime pada mesin cutting dan mesin welding. Selanjutnya dianalisis seluruh downtime dalam Root Cause Analysis(RCA) untuk mengetahui sebab terjadinya downtime, seperti ditunjukkan pada tabel 2.

Tabel 2. Root Cause Analysis Downtime Mesin Produksi

\begin{tabular}{|c|c|c|c|c|c|c|}
\hline Waste & Subwaste & Why-1 & Why-2 & Why-3 & Why-4 & Why-5 \\
\hline \multirow{9}{*}{ Waiting } & \multirow{5}{*}{$\begin{array}{l}\text { Downtime } \\
\text { Cutting }\end{array}$} & \multirow{3}{*}{$\begin{array}{l}\text { Komponen } \\
\text { elektronik } \\
\text { rusak }\end{array}$} & \multirow{2}{*}{$\begin{array}{l}\text { Elemen listrik } \\
\text { hangus }\end{array}$} & \multirow{2}{*}{$\begin{array}{l}\text { Kemampuan } \\
\text { mesin pemotong } \\
\text { kurang }\end{array}$} & $\begin{array}{l}\text { Daya mesin } \\
\text { kurang }\end{array}$ & $\begin{array}{l}\text { Pemilihan } \\
\text { Daya mesin }\end{array}$ \\
\hline & & & & & Kekerasan pisau & $\begin{array}{l}\text { Kesalahan } \\
\text { operator }\end{array}$ \\
\hline & & & Konsleting & kejutan arus & $\begin{array}{l}\text { stabilizer tidak } \\
\text { ada }\end{array}$ & \\
\hline & & $\begin{array}{l}\text { Motor } \\
\text { rusak }\end{array}$ & $\begin{array}{l}\text { Transmission } \\
\text { rusak }\end{array}$ & $\begin{array}{l}\text { Poros spindel } \\
\text { kotor }\end{array}$ & $\begin{array}{l}\text { poros spindel } \\
\text { tidak dibersihkan }\end{array}$ & \\
\hline & & $\begin{array}{l}\text { Motor } \\
\text { rusak }\end{array}$ & $\begin{array}{l}\text { Control tidak } \\
\text { berfungsi }\end{array}$ & $\begin{array}{l}\text { Kerusakan } \\
\text { komponen panel }\end{array}$ & $\begin{array}{l}\text { Kurangnya } \\
\text { maintenance }\end{array}$ & \\
\hline & \multirow{4}{*}{$\begin{array}{c}\text { Downtime } \\
\text { Welding }\end{array}$} & $\begin{array}{l}\text { Kerusakan } \\
\text { kabel }\end{array}$ & Sistem kendur & Benturan & $\begin{array}{l}\text { Penempatan mesin } \\
\text { tidak sesuai }\end{array}$ & \\
\hline & & \multirow{3}{*}{$\begin{array}{l}\text { Travo } \\
\text { converter } \\
\text { daya } \\
\text { hangus }\end{array}$} & $\begin{array}{l}\text { Suhu tidak } \\
\text { stabil }\end{array}$ & $\begin{array}{l}\text { pendinginan } \\
\text { rusak }\end{array}$ & $\begin{array}{l}\text { Sirkulasi tidak } \\
\text { baik }\end{array}$ & $\begin{array}{l}\text { debu kipas } \\
\text { tidak } \\
\text { dibersihkan }\end{array}$ \\
\hline & & & \multirow{2}{*}{$\begin{array}{l}\text { Hubungan } \\
\text { pendek }\end{array}$} & $\begin{array}{l}\text { Mesin las } \\
\text { terkena air }\end{array}$ & $\begin{array}{l}\text { Penempatan mesin } \\
\text { tidak sesuai }\end{array}$ & \\
\hline & & & & $\begin{array}{l}\text { Debu scrap yang } \\
\text { menumpuk }\end{array}$ & $\begin{array}{l}\text { tidak member } \\
\text { sihkan debu }\end{array}$ & \\
\hline
\end{tabular}

Akar penyebab defect waste dicari dari proses welding. Jenis defect yang terjadi pada proses welding diklasifikasikan menjadi dua jenis defect yaitu defect karena keretakan dan karena keropos pada hasil pengelasan. Dari penelusuran kecacatan dapat ditentukan bahwa 
proses pengelasan adalah proses yang menghasilkan produk cacat terbesar sehingga perbaikan akan dipusatkan pada proses ini.

Tabel 3. Failure Mode and Effect Analysis Defect Waste

\begin{tabular}{|c|c|c|c|c|c|c|c|c|}
\hline Waste & $\begin{array}{l}\text { Potential Failure } \\
\text { Mode }\end{array}$ & Potential Effect & Severity & Potential Causes & $\begin{array}{l}\text { Occu } \\
\text { rance }\end{array}$ & Control & $\begin{array}{l}\text { Detecti } \\
\text { on }\end{array}$ & $\begin{array}{l}R P \\
N\end{array}$ \\
\hline \multirow{8}{*}{ Defect } & \multirow{5}{*}{$\begin{array}{l}\text { Hasil } \\
\text { pengelasan } \\
\text { retak }\end{array}$} & \multirow{5}{*}{$\begin{array}{l}\text { Hasil } \\
\text { pengelasan } \\
\text { reject dan } \\
\text { harus } \\
\text { dilakukan } \\
\text { proses } \\
\text { pengelasan } \\
\text { ulang }\end{array}$} & 5 & $\begin{array}{l}\text { tidak melakukan } \\
\text { pemeriksaan } \\
\text { kandungan karbon } \\
\text { elektroda }\end{array}$ & 5 & $\begin{array}{l}\text { Analisa } \\
\text { lebih } \\
\text { lanjut }\end{array}$ & 5 & 125 \\
\hline & & & 5 & $\begin{array}{l}\text { Kemampuan operator } \\
\text { masih kurang }\end{array}$ & 4 & $\begin{array}{l}\text { Inspeksi } \\
\text { visual }\end{array}$ & 4 & 80 \\
\hline & & & 5 & $\begin{array}{l}\text { Pengetahuan operator } \\
\text { kurang }\end{array}$ & 6 & $\begin{array}{c}\text { Control } \\
\text { lapangan }\end{array}$ & 6 & 180 \\
\hline & & & 5 & $\begin{array}{c}\text { Skill operator kurang } \\
\text { dalam pengelasan }\end{array}$ & 6 & $\begin{array}{c}\text { Control } \\
\text { lapangan }\end{array}$ & 5 & 150 \\
\hline & & & 5 & $\begin{array}{c}\text { Kesalahan setting } \\
\text { mesin las }\end{array}$ & 4 & $\begin{array}{c}\text { Control } \\
\text { lapangan }\end{array}$ & 4 & 80 \\
\hline & \multirow{3}{*}{$\begin{array}{c}\text { Hasil } \\
\text { pengelasan } \\
\text { keropos }\end{array}$} & \multirow{3}{*}{$\begin{array}{c}\text { Hasil } \\
\text { pengela } \\
\text { san reject } \\
\text { dan } \\
\text { dilakukan } \\
\text { pengelasan } \\
\text { ulang }\end{array}$} & 5 & $\begin{array}{l}\text { Operator lupa } \\
\text { membersihkan }\end{array}$ & 5 & $\begin{array}{l}\text { Inspeksi } \\
\text { visual }\end{array}$ & 5 & 125 \\
\hline & & & 5 & $\begin{array}{c}\text { Kesalahan pemi lihan } \\
\text { elektroda }\end{array}$ & 5 & $\begin{array}{c}\text { Analisa } \\
\text { lanjut }\end{array}$ & 5 & 125 \\
\hline & & & 5 & $\begin{array}{c}\text { Kesalahan setting arus } \\
\text { las }\end{array}$ & 5 & $\begin{array}{l}\text { Control } \\
\text { lapangan }\end{array}$ & 5 & 125 \\
\hline
\end{tabular}

Dari timbulnya kecacatan maka dapat ditetapkan Critical to Quality (CTQ) untuk tiap proses yang kritis yaitu hasil pengelasan keropos dan hasil pengelasan keropos. Dengan telaah kecacatan di atas indikasi kecacatan dapat ditelusuri dari seluruh aktifitas nonvalue adding yang menyertainya. Aktifitas ini dalam konsep lean adalah merupakan waste (pemborosan).

Untuk perhitungan sigma level dan DPMO untuk proses pengelasan, dilakukan dengan bantuan SPC Wizard's Sigma Calculator. Jumlah produk cacat yang digunakan adalah semua produk yang dinyatakan cacat sesuai dengan standard kualitas yang ditetapkan oleh perusahaan. Dari tabel 3 ditunjukkan bahwa jumlah CTQ yang digunakan pada proses pemotongan sebanyak 2 CTQ, yaitu pengelasan retak dan pengelasan keropos.

Tabel 4. Konversi DPMO ke nilai Sigma

\begin{tabular}{|l|l|c|}
\hline Presentase yang memenuhi spesifikasi & DPMO & Sigma \\
\hline $30,9 \%$ & 690.000 & 1 \\
$69,2 \%$ & 308.000 & 2 \\
$93,3 \%$ & 66.800 & 3 \\
$99,4 \%$ & 6.210 & 4 \\
$99,98 \%$ & 320 & 5 \\
$99,9997 \%$ & 3,4 & 6 \\
\hline
\end{tabular}

Untuk perhitungan DPMO, data-data yang dibutuhkan adalah jumlah produk yang cacat (defects), jumlah produk yang diperiksa (units inspected) dan banyaknya CTQ penyebab kecacatan (opportunities per unit). 


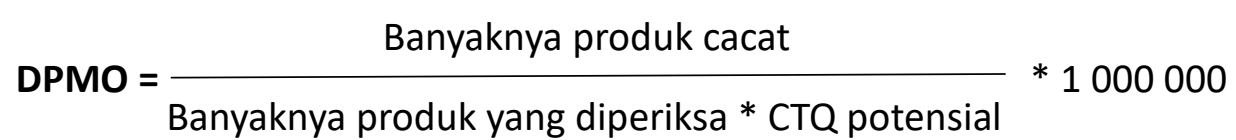

Dari perhitungan diperoleh bahwa sigma awal adalah 2,93 ini menunjukkan prosentase produk yang memenuhi spesifikasi yang diharuskan adalah sekitar 93\%, dan nilai Defect per million Opportunities adalah 69000.

DPMO mengindikasikan berapa banyak kesalahan muncul jika sebuah aktivitas diulang sebanyak sejuta kali [3]. Jika dalam perhitungan 6 sigma, dinyatakan bahwa perhitungan DPMO sebanyak 3,4 maka artinya dari produksi satu unit produk dalam prosesnya hanya memiliki 3,4 kali kesempatan untuk mengalami kegagalan. Perhitungan DPMO adalah sebagai berikut :

Berdasarkan pada analisa yang terdapat di FMEA, terdapat 3 alternatif yang mungkin dapat digunakan untuk melakukan improvement yaitu,

1. Pembentukan tim pembuatan SOP,

2. Penjadwalan maintenance mesin produksi dan

3. Pelatihan untuk meningkatkan knowledge, skills and abilities operator.

Terdapat tiga kriteria yang digunakan dalam penilaian keseluruhan alternatif yang mungkin dapat digunakan untuk dilakukan improvement, yaitu:

1. produktivitas,

2. kualitas dan

3. Cycle Time

Dari ketiga alternatif di atas, secara keseluruhan memiliki delapan kombinasi alternatif perbaikan yang dapat di-generate kan dan dipilih oleh perusahaan. Selanjunya untuk memilih alternatif terbaik dilakukan pendekatan value dengan mempertimbangkan dua faktor yaitu performance dan cost.

Bila seluruh solusi di atas dipakai sebagai dasar untuk membangun alternatif dan kombinasinya maka dapat dibuat 8 alternatif dan kombinasi alternatif yang berbeda. Setiap alternatif dapat ditelusuri berapa biaya yang dibutuhkan untuk menjalankan alternatif tersebut. Pada saat yang sama ketika alternatif dan kombinasi alternatif sudah terbentuk maka dibutuhkan penilaian performansi dari para ahli. Untuk menilai tiap alternatif dan kombinasinya ditentukan kriteria-kriteria penilaian. Setiap alternatif mempunyai komponen biaya dan performansi. Untuk memilih alternatif yang mungkin untuk dijalankan maka antara performansi dan biaya dipertimbangkan bersama-sama [17]. Tabel 5 menggambarkan alternatif yang mungkin untuk dijalankan dengan mempertimbangkan dua sisi yaitu biaya dan performansi.

Tabel 5. Value Pemilihan Alternatif

\begin{tabular}{|c|c|c|c|c|c|c|}
\hline \multirow{3}{*}{ Alternatif } & \multicolumn{3}{|c|}{ Bobot KPI } & \multirow{3}{*}{ Performance } & \multirow{3}{*}{ Cost (Rp.) } & \multirow{3}{*}{ Value } \\
\hline & Productivity & Quality & Cycle Time & & & \\
\hline & 0,4 & 0,3 & 0,3 & & & \\
\hline 0 & 12 & 13 & 15 & 13,2 & 123.015 .685 & 1 \\
\hline 1 & 21 & 18 & 19 & 19,5 & 140.015 .685 & 1,2978 \\
\hline 2 & 19 & 18 & 20 & 19 & 131.015 .685 & 1,3512 \\
\hline 3 & 20 & 20 & 18 & 19,4 & 128.861 .764 & 1,4030 \\
\hline 1,2 & 20 & 17 & 20 & 19,1 & 148.015 .685 & 1,2026 \\
\hline 1,3 & 24 & 22 & 21 & 22,5 & 145.861 .764 & 1,4378 \\
\hline 2,3 & 19 & 22 & 22 & 20,8 & 136.861 .764 & 1,4161 \\
\hline $1,2,3$ & 22 & 22 & 19 & 21,1 & 153.861 .764 & 1,2780 \\
\hline
\end{tabular}


Kombinasi alternatif 1 dan 3, berdasarkan perhitungan pada pendekatan value, yang paling tinggi diperkirakan akan dapat mereduksi cost seiring dengan penurunan rework dan defect product. Alternatif yang diajukan yaitu pembuatan dan pengawasan SOP, serta pengadaan pelatihan untuk meningkatkan skills, knowledge, and abilities setiap karyawan. Pada perhitungan awal, cost yang ditimbulkan akibat rework adalah Rp 3.831.494 sedangkan setelah dilakukannya kombinasi alternatif 1 dan 3, cost yang ditimbulkan adalah Rp 2873620,5 sehingga terjadi reduksi cost sebesar Rp 957 873,5 atau reduksi biaya $25 \%$.

Berdasarkan nilai sigma awal dari defect adalah 2,93 dan defect per million opportunities (DPMO) sebesar 69000 dan sigma setelah pelaksanaan kobinasi alternatif 1 dan 3 mempunyai nilai sigma sebesar 3,20 dengan defect per million opportunities (DPMO) sebesar 46 000; terjadi peningkatan nilai sigma terhadap Defect waste sebesar 0,27, dan terjadi penurunan nilai DPMO.

Bila penurunan defect per million opportunities (DPMO) ini ternyata belum dapat menutup biaya yang harus dikeluarkan untuk improvement maka strategi perbaikannya perlu untuk dirubah. Artinya diperlukan biaya yang lebih rendah untuk melakukan improvement.

Dari tabel di atas pengambilan keputusan terakhir, tergantung pada menejemen yang akan menjalankan perbaikan proses. Dengan perbaikan proses yang terus menerus (continous process improvement) diharapkan nilai sigma akan semakin baik.

\section{Kesimpulan}

Beberapa kesimpulan yang dapat diambil adalah:

1. Terdapat tiga waste yang muncul dan sering terjadi adalah over processing, defect, waiting waste.

2. Alternatif terpilih untuk melakukan mprovement yaitu pembuatan tim dan pengawas SOP serta pengadaan pelatihan guna meningkatkan kemampuan dan keterampilan tenaga kerja.

3. Terjadi kenaikan sigma dari sigma 2.70 menjadi 3.20 dan terjadi reduksi cost sebesar $25 \%$

\section{Daftar Pustaka}

[1] Timans, W., Ahaus, K., van Solingen, R., Kumar, M., \& Antony, J. (2016). Implementation of continuous improvement based on Lean Six Sigma in small-and medium-sized enterprises. Total Quality Management \& Business Excellence, 27(3-4), 309-324.

[2] Desai, D., \& Prajapati, B. N. (2017). Competitive advantage through Six Sigma at plastic injection molded parts manufacturing unit: A case study. International journal of lean six sigma, 8(4), 411-435.

[3] Cavanagh, R.R., Peter, S.P., and Robert, P.N. (2002). The Six Sigma Way, Penerbit Andi, Jogjakarta

[4] Evan, J.R. dan Linsay, W.M. (2007). Pengantar Six Sigma; An Introduction to Six Sigma and Process Improvement. Jakarta: Penerbit Salemba Empat.

[5] Antony, J., Kumar, M., \& Madu, C. N. (2005). Six sigma in small-and medium-sized UK manufacturing enterprises: Some empirical observations. International Journal of Quality \& Reliability Management, 22(8), 860-874.

[6] Albliwi, S. A., Antony, J., \& Lim, S. A. H. (2015). A systematic review of Lean Six Sigma for the manufacturing industry. Business Process Management Journal, 21(3), 665-691.

[7] Deolia, P., Verma, P. L., \& Bajpai, L. The Contribution of Total Quality Management And Six Sigma to Achieve the Success in Terms of Quality.

[8] Pyzdek, T. (2002). The Six Sigma Handbook: A Complete Guide for Greenbelts, Black belts, and Managers at all Levels, Tucson, Quality Publishing, Inc 
[9] Rathilall, R., \& Singh, S. (2018). A Lean Six Sigma framework to enhance the competitiveness in selected automotive component manufacturing organisations. South African journal of economic and management sciences, 21(1), 1-13.

[10] Girmanová, L., Šolc, M., Kliment, J., Divoková, A., \& Mikloš, V. (2017). Application of Six Sigma using DMAIC methodology in the process of product quality control in metallurgical operation. Acta technologica agriculturae, 20(4), 104-109.

[11] Bhote, K. R. (2003). The power of ultimate Six Sigma: Keki Bhote's proven system for moving beyond quality excellence to total business excellence. AMACOM Div American Mgmt Assn.

[12] Antony, J. (2011). Six Sigma vs Lean: Some perspectives from leading academics and practitioners. International Journal of Productivity and Performance Management, 60(2), 185-190.

[13] Gaspersz, V. (2007). Lean Six Sigma. Gramedia Pustaka Utama.

[14] Hines, P., \& Taylor, D. (2000). Going lean. Cardiff, UK: Lean Enterprise Research Centre Cardiff Business School, 3-43.

[15] Baker, B. (2003). Lean Six Sigma: Combining Six Sigma Quality With Lean Speed. Quality Progress, 36(10), 96.

[16] Andersen, B., \& Fagerhaug, T. (2006). Root cause analysis: simplified tools and techniques. ASQ Quality Press.

[17] Supriyanto, H., \& Maftuhah, D. I. (2017). A lean Six-Sigma manufacturing process case study. International Journal of Mechanical Engineering and Technology (IJMET), 8(7), 498-509.

[18] DaimlerChrysler Corporation; Ford Motor Company; General Motors Corporation (July 2001). Potential Failure Mode and Effects Analysis (FMEA), Reference Manual

[19] FMEA Worksheet, <URL:

www.ad12.k12.co.us/Quality/dokuments/FMEAWorksheet.pdf >

[20] Dighe, S. B., \& Kakirde, A. (2014). Lean manufacturing implementation using value stream mapping: A case study of pumps manufacturing company. International Journal of Science and Research, 3(6), 2492-2498. 